\title{
Images of Resilience: the Resilience Analysis Grid Applicable at several Organizational Levels?
}

\author{
Johan van der Vorm, Dolf van der Beek, Ellen Bos, Niek Steijger, Raphaël Gallis \\ and Gerard Zwetsloot \\ TNO, Hoofddorp, the Netherlands \\ johan.vandervorm@tno.nl
}

\begin{abstract}
Resilience engineering is a developing concept for coping with the changing world and growing complexity. TNO has begun a project to develop a tool with which to assess resilience. The aim is to enable companies to improve resilient practices at the organizational, team and individual level. The first phase of this project aims to set up a theoretical framework.

A diversity of sources was questioned for the available knowledge and a coherent framework to connect those levels. The Resilience Innovation Lab is used to share knowledge with expert members.

The four abilities of resilience in relation to supporting structure, culture and learning organization provide the key elements of the model that was developed. Attributes of resilience can be allocated at organizational, team and individual level. The resilience analysis grid provides a basis for developing an assessment tool for those levels. However the four abilities of resilience need to be analysed in closer detail and translated in measurable determinants together with the identification of resources for resilient performance in the next project phase.
\end{abstract}

\section{INTRODUCTION}

Traditional risk management falls short of improving safety in the changing world of work and fails to cope with its growing complexity of organizations (Groeneweg et al., 2010; Dekker et al., 2008). The diversity of concepts of resilience varies from abstract views to specific guidance with as many traditions and applications, e.g.: 1) High reliability organizations (HRO), security management, integral operations (Gifun \& Karydas, 2010; Weick \& Sutcliffe, 2001; Størseth et al., 2009); 2) System and resilience engineering (Dekker et al., 2008); and 3) Human factors engineering as well as positive psychological concepts connected with e.g. the profession of teachers (Johnson, 2009). Each of these applications reflects a different type of solution in terms of being proactive or adaptive, not only to prevent negative outcomes but also to support and strengthen positive outcomes of processes.

The definition of resilience used by several experts and followed by us, is "the 
intrinsic ability of a system to adjust its functioning prior to, during, or following changes and disturbances, so that it can sustain required operations even after a major mishap (or in the presence of continuous stress)" (Hollnagel, 2006; Dekker, 2008). Their view on resilience complements TNO research on safety@corebusiness by introducing dynamic relationships between structure, organizational learning and culture (Gort \& Starren, 2006; Zwetsloot et al., 2007).

Given the lack of useful methods and practical tools, TNO is undertaking a research and development project that aims at enabling: 1) the measurement and assessment of resilience at three levels: organization, team and individual; 2) the identification of resources to enhance resilience; and 3) the identification of methods to strengthen resilience. The study phase that is presented in this paper, aimed at building a theoretical foundation. The research questions are: a) Can studies/cases be identified in which the concept of resilience has been applied at the organization, team and individual levels; and b) Do these studies provide information on the relationships between the three levels, in order to facilitate functioning in a resilient way?

\section{METHODOLOGY}

The authors used three approaches to answer the research questions:

1. A literature review using SCOPUS between June 2010 and April 2011 (keywords: resilience (-t) safety, risk management, organization, hazard industry, socio-technical system, team performance, teamwork, team cooperation, team collaboration, engineering and resilience markers). This search was complemented with an internet search in the same period using Google (keywords: resilience (-t), safety, risk, organization, engineering, level,).

2. An analysis of the WIKI-s of the Resilience Innovation Lab, a web based platform (116 members) developed to share knowledge and to build up a shared vision and to create tools to assess and develop resilient risk management.

3. One workshop with HSE-managers of electricity companies and two attended by TNO experts that explored the relevance of resilience for business practices.

The project team used several exclusion criteria to select relevant articles, references from books etc. and questioned how they explain or provide evidence of resilience at the organizational levels identified and how they relate to one another.

\section{RESULTS}

\subsection{General results}

Our literature review revealed the lack of sophistication of research into the concept of resilience within safety research. Many papers are available on the subject of resilience as a concept, ability, capability, framework or mindset, but they are of a descriptive or conceptual nature as opposed to being high quality, peer-reviewed methodological studies. Several peer-reviewed papers included cases that applied the concept of resilience at the organizational, team and individual levels. However, these studies provided restricted information on how the three levels interrelate to one another in order to facilitate resilience. 


\subsection{The model developed}

The outcome of this study phase made it clear that safety is best developed through the interaction of organizational structure, culture and learning/adaptation as part of the primary process and management (Gifun \& Karydas, 2010; Jackson, 2009). Several sources identify the combination of culture, structure and resilience as factors that are relevant in supporting high reliable and complex organizations to fulfill their mission (Akselsson et al., 2009; Dekker et al., 2008). Resilience is subdivided into four abilities which are considered as the four cornerstones of resilience and are proposed as the core functionalities of operational resilience (Dekker et al., 2008; Hollnagel et al. 2011). For successful implementation to take place, these abilities should be based on a viable organizational system. Most experts argue that in order to develop resilience, proper resources are also necessary, for example in terms of supporting decision making, buffering and redundancy.

These aspects of resilience led to the design of a conceptual model, see figure 1 . Basic elements are: 1) the presence of the four abilities of resilience; 2) the need for supporting structure and culture; and 3) the identification and availability of relevant resources to promote and sustain resilience.

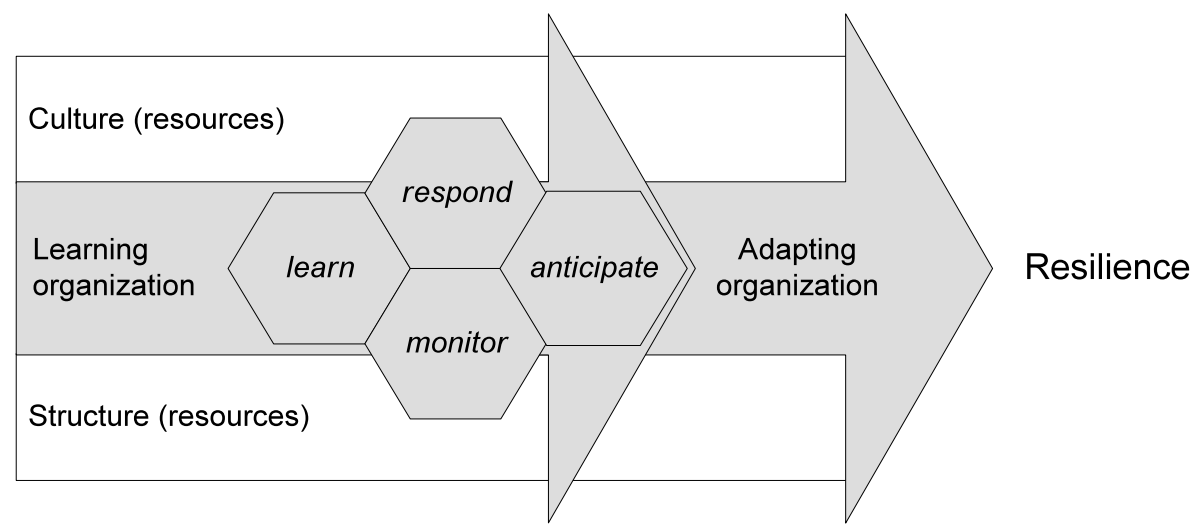

Fig. 1. Resilience defined by four abilities needs a supporting structure and culture

Resilience at recursive system levels of viable systems (Wreathall, 2008; Hollnagel et al., 2011) needs active coordination across all levels, activities and roles. Other authors (Størseth, 2009; Weick \& Sutcliffe, 2001; Tillement et al., 2009) also point out the relevance of intra- and inter-organizational relationships and dynamics (mindfulness, success factors for resilience, communication, situational awareness, decision support and continuous workflow). Cooperating teams in the primary process need support from coordination and communication structures, which requires a higher levels of organization (Cornelissen et al., 2010), see figure 2 .

The results of explorative dialogues and workshops with electricity companies confirmed the relevance of a multi-level approach to resilience. For example in the area of introducing alternative technology, windmill parks at sea and improving networks/contractor chains, building, strengthening maintenance teams working together with control rooms in connection with management of change. 


\subsection{Applying the resilience concept at the three levels}

\section{Organizational resilience}

Maintaining a resilient system requires a commitment by safety at the highest levels. Management has to stay aware of the system state variables, decrease the organization's mental workload, encourage a culture of openness and ensure that the necessary resources to handle serious events (Sheridan, 2008). This will mean that any deterioration in system performance can be anticipated early. This system of characteristics and strategies can be found within the organizational framework of HRO (Weick \& Sutcliffe, 2001) and resilience engineering (Hollnagel, 2006).

\section{Team resilience}

Teams are an important element in enhancing overall resilience (Steijger et al., 2010). They need to handle a wide variety of demands and must be able to call on a profound reservoir to prevent potential damage, take advantage of opportunities, or cope with (negative) consequences. Team resilience meets these demands (Morel et $a l ., 2008$ ). When managing (distributed) collective work in complex systems, multidisciplinary teams tend to use implicit, informal modes of control to solve problems (e.g. micro-incidents) rather than prescribed control mechanisms (e.g. operation standards) (Carvalho et al., 2005). Informal modes of control and of communication strategies facilitate the work. 'Listening in' on shared communication channels for supporting anticipation, contingency planning, detecting and recovering from errors is also important (as in Roth et al., 2006). These strategies save cognitive resources, are less time-consuming and increase the resilience of the team.

\section{Individual resilience}

At the individual level resilience meets resilience as a psychological construct. Resilience engineering at the individual level involves personal skills such as the ability to learn, respond and anticipate. For example Gu \& Day (2007) argue that teachers must be resilient in order to be effective. Portraits of three resilient teachers in their early, mid and late careers are used to explore the interaction between a teacher's sense of efficacy, professional and personal identities, and management of the interaction between these elements and the professional, situated and personal scenarios which they experience at each stage of their career. Teachers' capacity to manage this kind of interaction is a sophisticated process which contributes greatly to the relative strength of their resilience. Another sector with relational and public characteristics is healthcare. Matos et al. (2010) found a strong correlation between resilience and job satisfaction in the nursing profession.

\subsection{Interaction between organizational levels}

Resilience considered as a system characteristic (Hollnagel, 2006) implies functional relationships between levels in order to function; e.g. governance, coordination cooperation, communication, decision making authority (Dekker et al., 2008; Cornelissen et al., 2010; Gifun \& Karydas, 2010; Jackson, 2009; Øien et al., 2011).

A socially distributed system relies on mutually shared cognition to focus on the same goal, multiple and redundant sources of information (improving situational awareness), task take-over actions and workplace exchanges (Vidal et al., 2009). This improves foresight when coping with complex and unexpected events and increases overall organizational learning. Management should provide a working 
environment that enhances team coordination and cooperation processes (Sheridan, 2008). The use of transformational leadership behavior within teams promotes a rapid recovery after activities have been distorted (Schraagen \& Van der Kleij; submitted). A team provides a context for the individual, while an organization (team of team, project, chain, network, etc.) provides the context for the team.

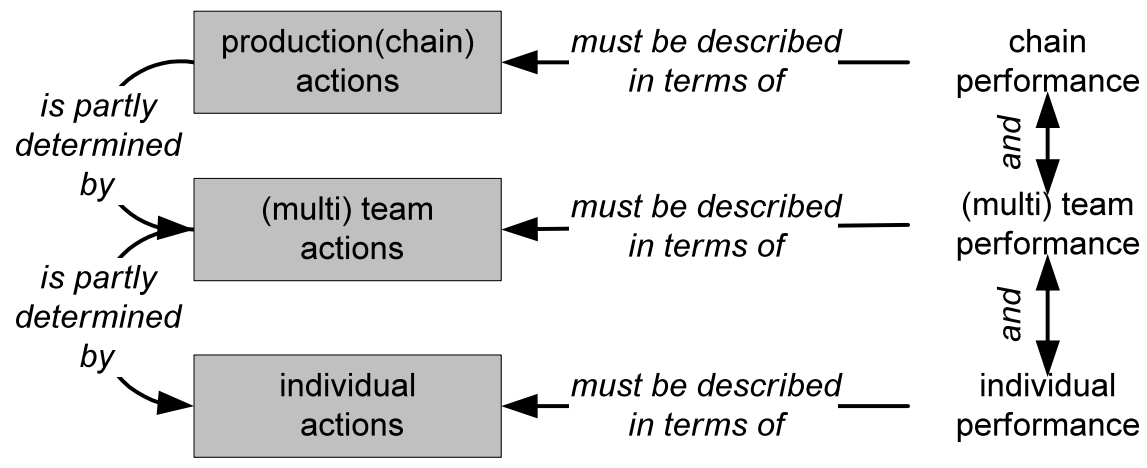

Fig. 2. Resilience assessed at organization levels (adapted from Dongen, 2010)

The organization culture connects all levels too. A reporting, learning, just or flexible culture is a prerequisite for the creation of openness to weak signals, diverse opinions, learning and being willing to modify risk models, being curious, openminded, sensitive, inviting of questions, and ambivalent toward the past (Weick 1987; 2001). Akselsson et al. (2009) see a resilient culture as necessary to strengthen safety management beyond present dominant concepts of safety culture.

\section{CONCLUSIONS}

Peer-reviewed papers were identified in which the concept of resilience has been applied at the organization, team and individual levels. However, such studies are still rare and provide restricted information about the relationships between the three levels in order to facilitate functioning in a resilient way. Resilience at the individual level remains an under-researched area. More research is necessary as well as a comprehensive research framework in which to study the concept of resilience within safety research. This will improve concept validity and the extent to which study results can be generalized.

This study shows that resilience is indeed a system characteristic that can be determined from the managerial level to the operational level. Resilience can be attributed to organizations, teams and individuals as well as to their interactions. The four abilities of resilience can be used as the basis for a coherent set of resilience markers, for which an assessment can be made. These abilities should be related to supporting structures and culture in order to become effective. Abilities, structure and culture all provide a basis for organizational learning and adaptability. However this capability can only be developed if all levels of organizations are involved and work together. The further development of the resilience analysis grid which takes these elements into account is considered a sound basis on which to develop an assessment tool for resilience aiming at bringing safety into the core business and providing the necessary flexibility for the development of business. 


\section{DISCUSSION}

The resilience analysis grid may provide a useful basis on which to assess resilience at the organization, team and individual levels. A first step would be to look for studies that discuss the application of the four abilities as a coherent set of functionalities and to analyse how they are applied at the three organizational levels. This must be connected with an assessment of a supporting structure and culture in order to assess the organizational conditions under which resilience can be successfully promoted and the identification of relevant determinants of resilience providing indicators for assessments needs to be defined. Further development of the Resilience Innovation Lab is needed to support open innovation in this project.

\section{REFERENCES}

Akselsson, R., Ek, Å, Koornneef, F., Stewart, S. \& Ward, M. (2009). Resilience safety culture. Paper presented at the 17th World Congress on Ergonomics, Beijing, China, Aug. 09-14.

Carvalho, P.V.R., dos Santosa, I.L. \& Vidal, M.C.R. (2005). Nuclear power plant shift supervisor's decision making during micro-incidents. International Journal of Industrial Ergonomics, 35, 619-644.

Cornelissen, M., Dongen, C.J.G. van, Ruiten, A.M. van, Kleij, R. \& Van der, Brake, G.M. te (2010). Een methodiek voor het meten en verbeteren van het functioneren van samenwerkingsverbanden van teams. TNO, Soesterberg, the Netherlands.

Dekker, S., Hollnagel, E., Woods, D. \& Cook, R. (2008). Resilience Engineering: New directions for measuring and maintaining safety in complex systems. Final Report, November 2008 Lund University School of Aviation.

Dongen, C.J.G. van (2010). Internal TNO document. Soesterberg the Netherlands.

Gifun, J. F. \& Karydas, D. M. (2010). Organizational Attributes of Highly Reliable Complex Systems. Quality and Reliability Engineering International, 26, 53-62.

Groeneweg, J., Van Schaardenburgh-Verhoeve, K.N.R. \& Corver, S.C. (2010). Widening the scope of accident investigations. Paper presented at the SPE International Conference on Health, Safety and Environment in Oil and Gas Exploration and Production, 12-14 April 2010.

Gort, J. \& Starren, A.M.L. (2006). Vanzelfsprekend veilig: veilig ondernemen als core business. TNO, Hoofddorp, the Netherlands.

Gu, Q. \& Day, Chr. (2007). 'Teachers resilience: A necessary condition for effectiveness'. Teaching and Teacher Education, 23, 1302-1316.

Hollnagel, E., (2006). Resilience: the challenge of the unstable. In: Hollnagel, E., Woods, D., Leveson, N. (Eds.), Resilience Engineering: Concepts and Precepts.

Ashgate, London, pp. 8-17.

Hollnagel, E., Pariès, J., Woods, D.D. \& Wreathall, J. (2011). Resilience Engineering in Practice, A Guidebook. Ashgate, Farnham.

Jackson, S. (2009). Architecting Resilient Systems: Accident avoidance and Survival and Recovery form Disruptions. Wiley and Sons.

Johnson B. \& Down, B. (2009). Critically re-conceptualizing early career teacher resilience. Paper presented at the European Conference on Educational Research, 
University of Vienna, Austria, 28th September.

Matos, P.S., Neushotz, L.A., Griffin, M.T. \& Fitzpatrick, J.J. (2010). 'An exploratory study of resilience and job satisfaction among psychiatric nurses working in inpatient units'. International Journal of Mental Health Nursing, 19, 5, 307-312.

Morel, G., Amalberti, R., \& Chauvin, C. (2008). Articulating the differences between safety and resilience: The decision-making process of professional seafishing skippers. Human Factors, 50, 1-16.

Øien, K. Utne, I.B., Tinmannsvik, R.K. \& Massaiu, S. (2011). Building Safety indicators: Part 2, Application, practices and results. Safety Science, 49, 162-171.

Resilience Innovation Lab retrievable from http://www.resilienceinnovationlab.org/.

Roth, E.M., Multer, J. \& Raslear, T. (2006). Shared situational awareness as a contributor to high reliability performance in railroad operations. Organization Studies, 27, 7, 967-987.

Schraagen, J.M. \& Van der Kleij, R. (submitted). Making teams more resilient: effects of shared transformational leadership training on resilience. Journal of Leadership and Organizational Studies.

Størseth, F. Øien, K. \& Tinmannsvik, R.K. (2009). Building Safety by resilient organization - a case specific approach. Paper presented at the safety and Reliability Association Annual Conference (ESREL), 7 - 10 September, 2009.

Sheridan, T.B. (2008). Risk, human error and system resilience: Fundamental ideas. Human Factors, 50, 3, 418-426.

Steijger, D.J.M, Van der Beek, F.A., Gallis H.R. \& Van der Vorm J.K.J, (2010). Resilience Risk Management: developing a model of resilient team performance to improve team effectiveness, Working On Safety 5th International Conference. 7-10 September 2010, Røros, Norway.

Tillement, S., Cholez, C. \& Reverdy, T. (2009). Assessing Organizational Resilience an Interactionist Approach. Management, 4, 12, 230-264.

Vidal, M.C.R. Carvalho, P.V.R., Santos, M.S. Santos, I.J.L. dos (2009). Collective work and resilience of complex Systems. Journal of Loss Prevention in the Process Industries, 22, 516-527.

Weick, K.E. (1987). 'Organizational Culture as a Source of High Reliability'. California Management Review, 29, 2, 112-127.

Weick, K.E. \& Sutcliffe, K.M. (2001). Managing the Unexpected: Assuring High Performance in an Age of Complexity. Jossey-Bass: San Francisco.

Woods, D.D., Hollnagel, E., 2006. Resilience engineering concepts. In: Hollnagel, E., Woods, D. \& Leveson, N. (Eds.), Resilience Engineering: Concepts and Precepts. Ashgate, Prologue, London, pp. 1-6.

Wreathall, J. (2008). Developing models for measuring resilience. Paper presented at 3rd Symposium in Resilience engineering Juan les Pin October 28-30 2008.

Zwetsloot G.I.J.M., Gort J., Zwanikken S., Steijger N., Van der Vorm J., Gallis R. \& Starren A, (2007). Safety in a complex world as the result of co-creation and colearning by key agents. Safety Science Monitor, 3, 4, 15 pages. 